\title{
Nanocrystalline Copper Oxide(II)-Catalyzed Alkyne-Azide Cycloadditions
}

\author{
Young-Jin Song, Chungyul Yoo, Jong-Tai Hong, Seung-Joo Kim, Seung Uk Son, ${ }^{\dagger}$ and Hye-Young Jang ${ }^{\star}$

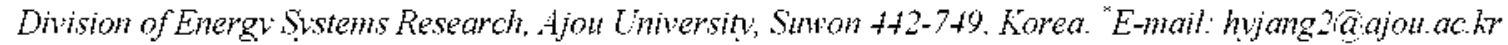 \\ ${ }^{\dagger}$ Deparment of Chemistry, Sungkwnhwan Chiversin, Suwon $1+0-7+6$. Korea \\ Received Julv 1. 2008
}

\begin{abstract}
Although the use of $\mathrm{Cu}$ (II) salts as cataly sts without reductants is limited in the cycloaddition of acetylenes with azides, the catalytic system employing average 10 nun CuO(II) nanoparticles in the absence of reductants shows good catalytic activity to form 1,4-disubstituted 1.2,3-triazoles even in wet THF as well as water. It is also noticeable that $\mathrm{CuO}$ (II) nanoparticle catalysts can be recycled with consistent activity. A range of alkynes and azides were subject to the optimized $\mathrm{CuO}$ (II) nanoparticle-catalyzed cycloaddition reaction conditions to afford the desired products in good yields.
\end{abstract}

Key Words : Click chemistry, Copper oxide nanoparticles. Cycloaddition. Heterogeneous catalỵsis

\section{Introduction}

The copper catalyzed Huisgen 1,3-dipolar cycloaddition reaction of azides and terminal alkynes, as a representative example of click chemistry. has made a great impact on biological. industrial and synthetic applications. ${ }^{1.2}$ This reaction provides synthetically and biologically useful $1.2,3$ triazole type products with high regioselectivity and is also tolerant to a wide range of functional groups and reaction conditions involving air and water.

To perform this transformation. commercially available $\mathrm{Cu}(\mathrm{D})$ salts and $\mathrm{Cu}$ (I) species. generated in situ from $\mathrm{Cu}(\mathrm{II})$ salts in the presence of sodium ascorbate. have been widely used assuming that copper (D) species are catalytically competent in the homogeneous reactions. ${ }^{1 c .3}$ Alternatively. heterogeneous $\mathrm{Cu}$ catalysts e.g. $\mathrm{Cu} / \mathrm{Cu}_{2} \mathrm{O}$ nanoparticles. $\mathrm{Cu}$ in charcoal, and $\mathrm{Cu}$ nanoclusters are also reported. ${ }^{4}$ In addition to $\mathrm{Cu}(\mathrm{I})$ cataly sts and heterogeneous $\mathrm{Cu}$ catalysts. $\mathrm{Cu}(\mathrm{OAc})$ : was reported as a catalyst for the cycloaddition of azides and acetylenes in the absence of sodium ascorbate. However, drawbacks of this catalytic system are high cataly st loadings ( $20 \mathrm{~mol} \%$ ) and low yield compared to that of $\mathrm{Cu}(\mathrm{I})$ catalyzed reactions. ${ }^{5}$ Accordingly. we are encouraged to explore low-cost. highly efficient, and environmental friendly cycloaddition protocols using $\mathrm{Cu}$ (II) nanoparticles.

The objectives of catalysis involving nanoparticles are not only to achieve high activities and selectivities resulting from the enlarged surface area but also take advantage of the recyclability of them. ${ }^{6}$ Together with the studies pertaining to novel chemical properties of nanoparticles, the development of new nano-catalysts with an excellent level of performance over a wide range of chemical transformations has been an on-going theme in the catalysis area. As a result. many other metal and metal oxide nanoparticles (e.g., Pd. $\mathrm{Au}, \mathrm{Cu} . \mathrm{Co}, \mathrm{Rh}, \mathrm{ZnO} . \mathrm{MgO}$ ) have been utilized as cataly sts in various organic reactions. ${ }^{6,7}$ Annong then. the use of $\mathrm{CuO}$ (II) nanoparticles is limited to industrial and environmental chemistry involving decomposition, reduction and oxidation reactions and a few recent coupling reactions. ${ }^{8.9}$
In the present work, we have demonstrated the excellent catalytic activity of $\mathrm{CuO}$ (II) nanoparticles in the Huisgen cycloaddition reaction of azides and acetylenes. It is noteworthy that the catalytic activity of $\mathrm{Cu}$ (II) species is remarkably improved by controlling the particle size, resulting in no use of reductants and the good chemical yield over other $\mathrm{Cu}$ (II) salts catalyzed reactions. Indeed, the use of cheap. stable and recyclable heterogeneous $\mathrm{CuO}$ (II) nanoparticles allows this reaction to be a clean and economical catalytic process.

\section{Results and Discussion}

The $\mathrm{CuO}(\mathrm{II})$ nanoparticles were prepared by the precipitation method ${ }^{\text {ji }}$ and characterized by powder $X$-ray diffraction spectroscopy (XRPD), transmission electron microscopy (TEM) and thermogravimetric analysis. The XRPD pattern, shown in Figure 1, displays that $\mathrm{CuO}$ (II) nanoparticles are composed of the single-phase $\mathrm{CuO}$ (II) with monoclinic structure (JCPDS\# 45-(1937) without any contamination of $\mathrm{Cu}_{2} \mathrm{O} .{ }^{11}$ The $\mathrm{CuO}$ (II) particles have a spherical shape with the average size of $10 \mathrm{~nm}$ as shown in the TEM image (Fig. 2a). The phase purity of $\mathrm{CuO}$ (II)

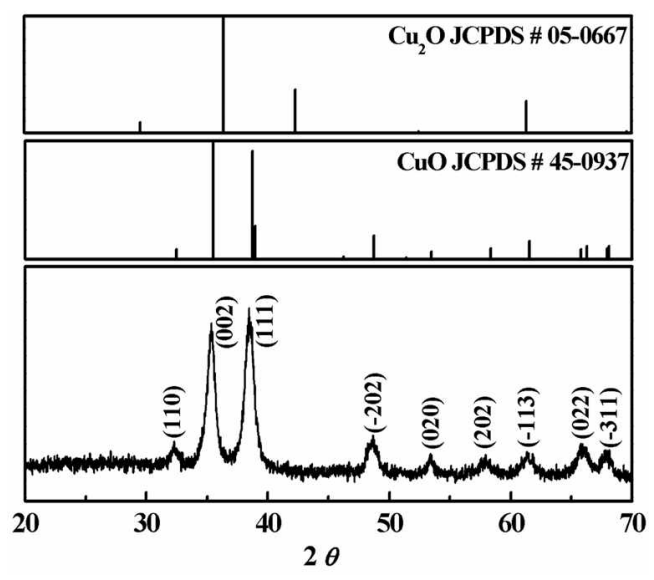

Figure 1. The XRPD pattem of $\mathrm{CuO}(\mathrm{II})$ nanoparticles. 
(a)

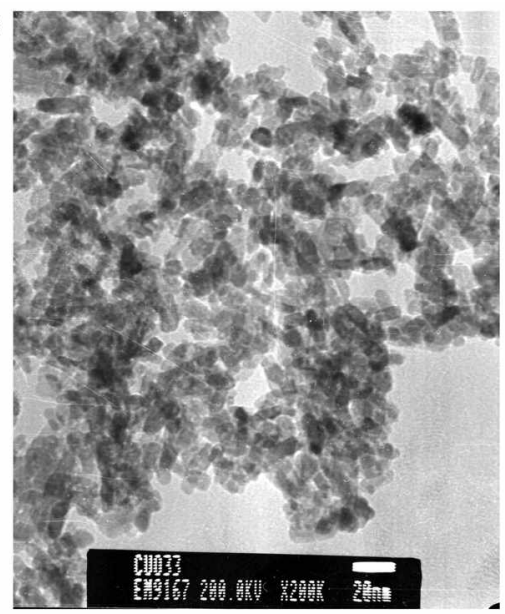

(b)

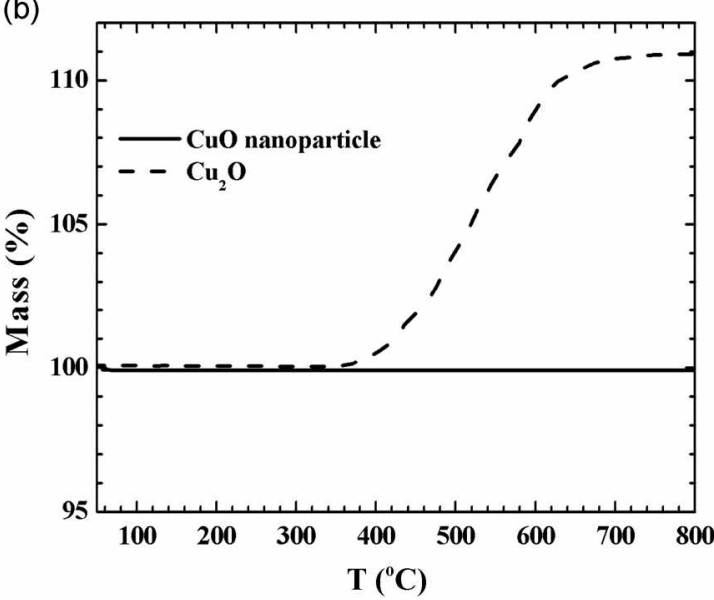

Figure 2. The TEM image (a) and the thermogravimetric (TG) analysis of $\mathrm{CuO}(\mathrm{II}$ ) nanoparticles under ambient atmosphere (b). For conparison, the $\mathrm{TG}$ curve for conmercial $\mathrm{Cu}_{2} \mathrm{O}$ powder (Adrich) is also represented.

nanoparticles was confirmed with thermogravinetric analysis. No change of the sample weight over the range of temperature from $50^{\circ} \mathrm{C}$ to $800^{\circ} \mathrm{C}$ indicates that $\mathrm{CuO}$ (II) nanoparticles do not contain any secondary phase such as $\mathrm{Cu}=\mathrm{O}$ (Fig. 2b)

In the context of utilizing $\mathrm{CuO}$ (II) nanoparticle-catalysts without reductants for the Huisgen cycloaddition and expanding the solvent scope of the Huisgen cycloaddition other than water. the following reaction conditions were examined. As indicated in Table 1. to iniprove the dispersion of nanoparticles in the solvent. the reaction mixture was sonicated for 10 minutes prior to raising the temperature to $60^{\circ} \mathrm{C}$. The cycloaddition reaction of benzyl azide ( $1 \mathrm{mmol}$. $100 \mathrm{~mol} \%)$ and phenylacetylene $(1.5 \mathrm{mmol} .150 \mathrm{~mol} \%)$ with $\mathrm{CuO}$ (II) nanoparticles $(0.05 \mathrm{mmol}, 5 \mathrm{~mol} \%)$ in THF from the shelf afforded 1.4-disubstituted 1,2.3-triazoles as a single regioisomer $(63 \%$ yield). Considering the hygroscopic property of THF, it is expected that the reaction conditions need to be optimized by controlling the amount of water (Table 1). Initially, the optimization was carried out in anhyydrous THF ( $2.5 \mathrm{~mL} .0 .4 \mathrm{M}$ ) purchased from Aldrich to afford the product in $41 \%$ yield (entry 1. Table 1). This result led us to consider that the andydrous reaction conditions might diminish the catalytic activity of $\mathrm{CuO}$ (II) nanoparticles. To prove this hypothesis. $0.1 \mathrm{~mL}$ of water $(\mathrm{v} / \mathrm{s}$ $4 \%$ ) was used as an additive. Under reaction conditions insolving a small amount of water ( $/ / v 4 \%)$. the yield was increased to $95 \%$ (entry 2. Table 1). However adding more water ( $\mathrm{v} / \mathrm{v} 20 \%$ ) induced the lower yield (entry 3 . Table 1 ). Based on the water effect in THF. other organic solvents were screened with water and without water. Unfortunately. both toluene and dioxane appeared to be less effective than THF, yet water additives improved the yield compared to the anlhydrous reaction conditions (entry 4-7. Table 1). In addition to organic solvents. water as a generally applied solvent in this transformation was tested. The cycloaddition reaction in water provided the desired product in $76 \%$ yield (entry 8. Table 1).

Another advantage of using heterogeneous nanoparticles is the recyclability. To test the recyclability of this system. recovered $\mathrm{CuO}$ (II) catalysts were exposed to the standard reaction conditions. exhibiting an excellent reactivity (entry 9. Table 1). The XRPD pattern of the recovered catalyst shows the structure of $\mathrm{CuO}$ (II) nanoaprticles has not been changed by water and other reactants during the catalytic process. Regarding the amount of catalysts, it was found that reduced catalyst loadings ( $3 \mathrm{~mol} \%$ ) did not affect the yield of the reaction (entry 10, Table 1). Next. the catalytic activity of commercial $\mathrm{CuO}$ (II) powder purchased from Aldrich (ACS reagent $99.0 \%$. particle size $<5$ micrometer) was tested resulting in $7 \%$ isolated yield. while under similar conditions $\mathrm{CuO}$ (II) nanoparticle-catalyzed the reaction provided $95 \%$ of the product (entry 11. Table 1). Presumably, this difference is attributed to the larger contact area of $\mathrm{CuO}$ (II) nanoparticles, eventually accelerating the

Table 1. Optimization of cycloaddition catalyzed by CuO(II) nanoparticles

\begin{tabular}{|c|c|c|c|}
\hline & $\mathrm{N}_{3}$ & $\begin{array}{c}\text { CuO nanoparticles (NAP) } \\
\text { solvent } \\
60^{\circ} \mathrm{C}\end{array}$ & $-N$ \\
\hline 1try & Catalyst & Solvent & Yield \\
\hline 1 & CuO(NAP) 5 mol\%) & 24 h THF $(0.4 \mathrm{M})$ & $41 \%$ \\
\hline 2 & $\mathrm{CuO}(\mathrm{NAP})(5 \mathrm{~mol} \%)$ & 24 h THF: $\mathrm{H}_{2} \mathrm{O} 24: 1(0.4 \mathrm{M})$ & $95 \%$ \\
\hline 3 & CuO(NAP) $5 \mathrm{~mol} \%)$ & 24 h THF: $\mathrm{H}_{2} \mathrm{O}$ & $47 \%$ \\
\hline 4 & CuO(NAP) $(5 \mathrm{~mol} \%)$ & 24 h toluene (s & $33 \%$ \\
\hline 5 & CuO(NAP) $(5 \mathrm{~mol} \%)$ & 24 h toluene: $\mathrm{H}_{3}$ & $54 \%$ \\
\hline 6 & CuO(NAP) 5 mol\%) & 24 h diosane $(0$ & $14 \%$ \\
\hline 7 & CuO(NAP) $5 \mathrm{~mol} \%)$ & $24 \mathrm{~h} \mathrm{~d}$ & $30 \%$ \\
\hline 8 & CuO(NAP) 5 mol $\%)$ & 24 h $\mathrm{H}_{2} \mathrm{O}(\mathrm{C}$ & $76 \%$ \\
\hline 9 & CuO(NAP) $(5 \mathrm{~mol} \%)^{a}$ & $24 \mathrm{~h}$ THF: $\mathrm{H}_{2} \mathrm{O}$ & $97 \%$ \\
\hline 10 & $\mathrm{CuO}(\mathrm{NAP})(3 \mathrm{~mol} \%)$ & 24 h THF: $\mathrm{H}_{2} \mathrm{O} 2$ & $95 \%$ \\
\hline 11 & CuOpowder $\times(5 \mathrm{~mol} \%$ ) & $24 \mathrm{~h}$ THF: $\mathrm{H}_{2} \mathrm{O} 24: \mathrm{I}(0.4 \mathrm{M})$ & $7 \%$ \\
\hline 12 & No catalyst & 24 h THF: $\mathrm{H}_{2} \mathrm{O} 24: 1(0.4 \mathrm{M})$ & $2 \%$ \\
\hline
\end{tabular}

The reaction was sonicated for 10 minutes prior to increasing the temperature. The cyclized products of all entries were obtained as single regioisomer: ${ }^{a}$ Recycled $\mathrm{CuO}$ nanoparticle catalysts were used. 
Table 2. The scope of substrates

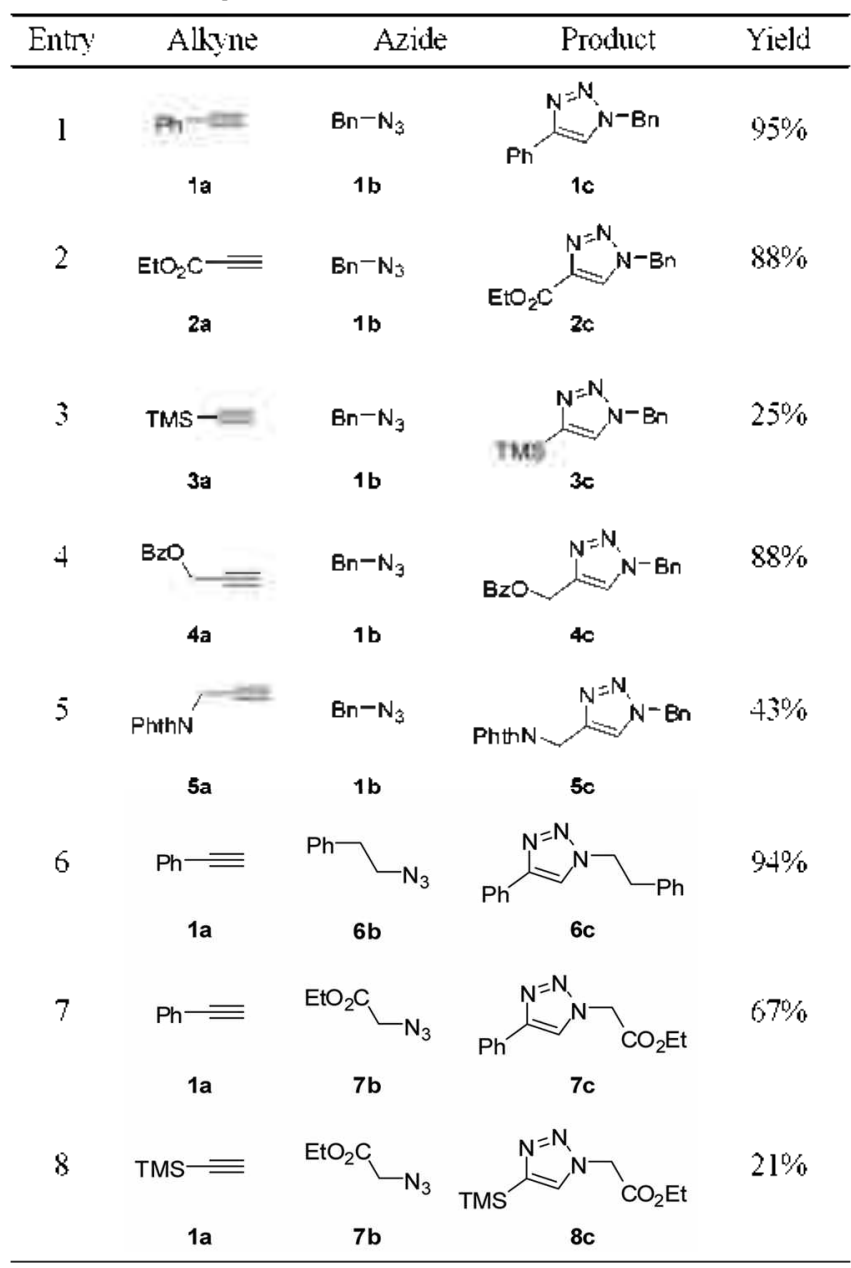

desired cycloaddition process. In the absence of the cataly st. this reaction does not appear to occur efficiently (entry 12 . Table 1). Throughout the optimization. the reaction conditions involving $5 \mathrm{~mol} \%$ of $\mathrm{CuO}$ (II) nanoparticle-catalysts using wet THF were chosen as standard conditions for further reactions (entry 2. Table 1).

To explore the scope of the substrates. various alkynes and azides were subject to the standard CuO(II) nanoparticlescatalyzed crcloaddition conditions. Since the functional groups on the substrates are known to play a significant role in terms of the yield and selectivity initially, alkynes possessing different groups were examined (Table 2). Ethyl propiolate 2a whose alkyne is adjacent to electron withdrawing group (ester) underwent the cycloaddition reaction with benzyl azide $\mathbf{1 b}$ to afford the product $\mathbf{2} \boldsymbol{c}$ in $88 \%$ : however. ethỵyltrimethỵlsilane $3 a$ possessing silicon next to the acetylene reacted with benzyl azide $\mathbf{1 b}$ to provide the desired product $3 \mathrm{c}$ in $25 \%$ yield under the same reaction conditions. Prop-2-ynyl benzoate 4 a containing benzoyl protected alcohol participated in this transfomation to provide the product $4 \mathrm{c}$ in $88 \%$. $N$-propargy lphthalimide $\mathbf{5 a}$ showed somewhat lower reactivity although the structure of substrate 5a seems similar to substrate 4 a possessing a heteroatom at the propargy lic position.
Subsequent to the screen of acetylenes. different azides possessing different functional groups were used (Table 2). (2-Azidoethyl)benzene $\mathbf{6} \mathbf{b}$ reacted with phenyl acetylene to show the comparable yield $(94 \%)$ with respect to the reaction of benzyl azide $1 \mathrm{~b}$ and phenylacetylene $(95 \%)$ Ethyl 2-azidoacetate $7 \mathbf{b}$ having ethyl acetate was exposed to the standard conditions to provide the product in $67 \%$ yield. The diminished reactivity of ethyl 2-azidoacetate was not improved by changing the acetylene partner to ethynyl trimethyl silane. In view of these results, most cycloaddition reactions involving different acetylenes and azides show moderate to good yields except for the reaction using ethynyltrimethỵlsilane.

\section{Conclusions}

In summation. CuO(II) nanoparticles have been used for the catalytic cycloaddition reaction of azides and acetylenes to provide the cyclized products in good yields with high regioselectivity. By employing nanocry stalline cataly sts. the catalyst activity was remarkably improved compared to micro size $\mathrm{CuO}$ (II). In addition, $\mathrm{CuO}$ (II) nanoparticlecatalysts were recycled to catalyze the cycloaddition with the consistent reactivity under standard reaction conditions.

\section{Experimental Section}

Anhydrous THF ( $99.9 \%$ inhibited with $0.025 \%$ BHT) was purchased from Aldrich and used without extra purification Proton nuclear magnetic resonance ( ${ }^{H} \mathrm{H}$ NMR) spectra were recorded with a Varian Mercury plus $(400 \mathrm{MHz})$ spectrometer. Chemical shifts are reported in delta $(\delta)$ units. part per million (ppm) downfield from trimethylsilane. Coupling constants are reported in Hertz (Hz). Carbon-13 nuclear magnetic resonance $\left({ }^{13} \mathrm{C}\right.$ NMR) spetra were recorded with a Varian Mercury plus $(100 \mathrm{MHz})$ spectrometer. Chemical shifts are reported in delta $(\delta)$ units. part per million (ppm) relative to the center of the triplet at $77.00 \mathrm{ppm}$ for deuteriochloroform. Infrared spectra were recorded on a MAGNA-IR560. High-resolution mass spectra (HRMS) are obtained on a JMS700 spectrometer (Korean basis science institute). $\mathrm{CuO}$ (II) nanoparticles were characterized by XRPD (Rigaku DMAX-2200PC diffractometer using CuK radiation). TEM (JEOL-2000EXII) and thenmogravimetric analy sis (MAC TG-DTA 2010). Substrates 4a. 5a. 1b. 6b. and $7 \mathrm{~h}$ were prepared according to the previously reported procedures. 1? Products $\mathbf{1 c}-\mathbf{3 c}$ and $\mathbf{5 c - 7 c}$ exhibited spectral properties consistent with previous literature reports. ${ }^{\text {lit }}$

Synthesis of CuO(II) nanoparticles. Copper acetate ( $1.0 \mathrm{~g}$ ) and acetic acid $(1.0 \mathrm{ml})$ were dissolved in $250 \mathrm{~mL}$ of distilled water. The solution was heated to $100^{\circ} \mathrm{C}$ before a rapid introduction of $0.8 \mathrm{~g}$ of $\mathrm{NaOH}$ flakes with vigorous stirring. After being cooled to room temperature, black powders precipitated were separated by centrifugation at $10000 \mathrm{rpm}$ for $10 \mathrm{~min}$. then washed several times with distilled water and ethanol and dried at $130^{\circ} \mathrm{C}$ for $12 \mathrm{~h}$.

The representative procedure for the cycloaddition 
reaction. To a solution of phenyl acetylene (133 $\mathrm{mg} .1 .5$ mmol. $150 \mathrm{~mol} \%$ ) and benzyl azide ( $153 \mathrm{mg} .1 \mathrm{mmol}, 100$ $\mathrm{mol} \%)$ in THF $(2.4 \mathrm{~mL})$ at ambient temperature was added $\mathrm{CuO}$ (II) nanoparticles (3.97 $\mathrm{mg}, 0.05 \mathrm{mmol}, 5 \mathrm{~mol} \%$ ) and water $(0.1 \mathrm{~mL})$. The system was purged with nitrogen gas and the reaction was allowed to stir at $60^{\circ} \mathrm{C}$ for 24 hours. then the reaction mixture was evaporated onto silica gel and the product purified via silica gel chromatography.

The recovery procedure of $\mathrm{CuO}$ (II) nanoparticles. Upon the completion of the reaction, the solution containing the product was decanted. Subsequently, fresh THF was added into $\mathrm{CuO}$ (II) nanoparticles and the resulting solution was stirred for 10 minutes with sonication. Then. the THF layer was decanted. This washing process was repeated twice. After drying the $\mathrm{CuO}$ (II) nanoparticles under vacuum for 10 minutes, the cycloaddition reaction was performed with the recovered $\mathrm{CuO}$ (II) nanoparticles.

1-Benzyl-1 H-1,2,3-triazol-t-yl)methyl benzoate $(+c)$. ${ }^{1} \mathrm{H} \mathrm{NMR}\left(\mathrm{CDCl}_{3}\right): \delta=8.0 \mathrm{l}(\mathrm{d}, J=7.2 \mathrm{~Hz} .2 \mathrm{H}) .7 .60(\mathrm{~s}, \mathrm{H})$. 7.45 (m. $3 \mathrm{H}), 7.3 \mathrm{l}$ (m. $5 \mathrm{H}), 5.5 \mathrm{l}$ (s. $2 \mathrm{H}), 5.43$ (s. $2 \mathrm{H}$ ) ppm. ${ }^{13} \mathrm{C}$ NMR $\left(\mathrm{CDCl}_{3}\right): \delta=166.5 .143 .5 .134 .5$. 133.4. 129.9 . 129.3. 129.0. 128.5, 128.3. 124.0, 58.4, 54.6, HRMS [M] ${ }^{+}$ calcd: 293.12 , obsd: 293.12 . IR: $3060,2360.1710,1270$. $1100 \mathrm{~cm}^{-1}$.

Ethyl 2-(4-(trimethylsilyl)-1H-1,2,3-triazol-1-yl)acetate (8c). ${ }^{1} \mathrm{H} \mathrm{NMR}\left(\mathrm{CDCl}_{3}\right): \delta=7.65$ (s. $\mathrm{lH}$ ). 5.12 (s. $2 \mathrm{H}$ ). 4.25 (q. $J=6.8 \mathrm{~Hz} .2 \mathrm{H}$ ). 1.30 (t. $J=6.8 \mathrm{~Hz}, 3 \mathrm{H}$ ), 0.33 (s. $9 \mathrm{H}$ ) ppm. ${ }^{13} \mathrm{C}$ NMR $\left(\mathrm{CDCl}_{3}\right): \delta=166.6 .130 .4 .128 .9,62.6 .50 .6$. $14.5,0.7$. HRMS $[\mathrm{M}+\mathrm{H}]^{-}$calcd: 228.12 obsd: 228.12 . IR: $2960.2360,1750,1650,1210 \mathrm{~cm}^{-1}$.

Acknowledgments. This work was supported by the Korea Science and Engineering Foundation (grant No. R012007-000-20223-0) and the Korea Research Foundation (grant No. KRF-2007-412-J04003).

\section{References}

1. (a) Kolb. H. C.: Finn, M. G: Sharpless, K. B. Angew. Chem. Int Ed. 2001. 40, 2004. (b) Kolb, H. C.: Sharpless. K. B. Drug Discov: Toda 2003, 8. 1128 . (c) Bock. V. D.: Hiemstra. H: van Maarseveen. J. H. Eur, J. Org. Chem 2006. 51. (d) Sharpless. K. B.: Fokin. V. V.: Green. L. G.: Rostovtsev. V. V. Angew: Chent. Int. Ed. 2002. 41.2596. (e) Meldal. M.: Christensen. C.: Tornoe. C. W. J. Org. Chem. 2002, 67, 3057. (f) Yan, Z.-Y.: Zhao. Y.-B: Fan. M.J.: Liu, W.-M.: Liang. Y.-M. Terohedron 2005. 61,9331.

2. (a) Buckle. D. R.: Rockell C. I. M. J. Chem. Soc. Perkin Trans. I 1982. 627. (b) Alvarez. R.: Velazquez. S.: San-Felix. A.: Aquaro. S.: De Clereq. E.: Perno. C.-F.: Karlsson. A.: Balzarini. J.: Carmarasa. M. J. J. Hed. Chem, 1994. 37. 4185. (c) Wang. Q: Chan, T. R: Hilgraf. R.: Fokin, V. V.: Sharpless. K. B.: Finn. M. G. J. Am. Chem. Soc. 2003. 125.3192 (d) Speers, A. E.: Adam, G. C.: Cravatt. B. F. J. Am. Chem. Soc. 2003. 125. 4686. (e) Lee. L. V: Mitchell. M. L.: Huang. S.-J.: Fokin. V. V.: Sharpless. K. B.: Wong. C.-H. J. Am. Chem. Soc. 2003. 255.9588 . (t) Link. A. J.: Vink. M. K. S.: Tirrell. D. A. J . Am. Chem. Soc. 2004. 126. 10598. (g) Chan, T. R: Hilgraf. R: Sharpless. K. B.: Fokin. V. V. Org. Lett. 2004. 6. 2853 .

3. (a) Pérez-Balderas F.: Ortega-Munoz. M: Morales-Sanfrutos. J: Hernández-Mateo. F.: Calvo-Flores. F. G.: Calvo-Asin. J. A.: IsacGarcia. J.: Santovo-Gonzalez. F. Org. Lett. 2003. 5. 1951. (b)
Himo. F.: Lovell. T.: Hilgraf. R.: Rostontsev. V. V: Noodlemant. L.: Sharpless. K. B.: Fokitr. V. V. J. An. Chem. Soc. 2004. 126 210. (c) Lewis. W. G.: Magallon. F. G.: Fokin. V. V.: Fint1. M. G. $J$ Am. Chem. Soc, 2004, 126, 9152 . (d) Lutz. J.-F: Börner, H. G.; Weichenhan, K. Hacmonol Rapid Commm. 2005. 26,514, (e) Gerard, B.; Rvan. J.: Beeler, A. B.; Porco Jr.. J. A. Tetohedem 2006. 62. 64015. (f) Díez-González. S.: Correa. A.: Cavallo. L: Nolant. S. P. Chem. Eur, J. 2006. 7558. (g) Nolte. C.: Mayer. P.: Straub. B. F. Angew. Chem. Int Ed 2007. 16.2101.

4. (a) Pachón. L. D.: van Maarseveen, J. H; Rothenberg. G. Adr Sunth. Catal 2005. 347.811. (b) Orgueira. H. A.: Folas, D: Isome. Y.: Chan. P. C.-M.; Baldino, C. M. Tetohedron Lett 2005. 46. 2911. (c) Molteni. G.: Bianchi. C. L.: Marinoni. G.: Santo. N.: Ponti. A. New J. Chent 2006. 30. 1137. (d) Lipshutz. B. H.: Taft. B. R. Angew. Chem. Int. Ed. 2006. +5. 8235. (e) Girard. C.: Önet1. E; Aufort. M: Beauvière. S: Samson, E.: Herscovici, J. Org. Lett. 2006, 8, 1689. (f) Kantam. M. L. Jaya, V. S.: Sreedhar. B.: Rao. M. N.: Choudary, B. M. J. Hol Catalysis A: Chemical 2006. 256. 273. (g) Chassaing. S.: Kumarraja. M.: Sido. A. S. S.: Pale. P.: Sommer. J. Org. Letf. 2007. 9.883.

5. (a) Ye. M.-C.: Zhou. T.: Huang. Z.-Z.: Tang. Y. Chent Conmum. 2003. 2554. (b) Park. S. Bi, Alper, H. Chem. Commun 2005. 1315. (c) Reddy. K. R.: Rajgopal, K, Kantam, M. L. Symlett 2006. 957.

6. Review articles: (a) Gladysz. T. A. Pure Appl Chem. 2001. 73. 1319. (b) Gladysz. T. A. Chem. Rev 2002. 102. 3215. (c) Bell. A T. Science 2003. 299. 1688. (d) Schlögl. R.: Hamid. S. B. A. Angew: Chem Iht Ed 2004. 43,1628 . (e) Haruta M. CATTECH 2002. 6,102 .

7. (a) Choudary, B. M.: Mulukutla, R. S.: Klabunde. K. J. J. Am Chent Soc. 2003. 125. 2020. (b) Sarvari. M. H.: Sharghi. H. J. Org. Chent 2004. 69.6953. (c) Choudary. B. M.: Kantam. M. L.: Ranganath. K. V. S.: Mahender. K.: Sreedhar. B. J. Ant Chent. Soc, 2004. 126, 3396. (d) Choudary. B. M. Ranganath, K. V. S. Pal. U.: Kantam, M. L.: Sreehar. B. J. Am. Chem. Soc. 2005. 127. 13167. (e) Choudary, B. M.: Mahendar. K: Kantam. M. L: Ranganath. K. V. S.: Athar. T. Ach: Swh Catal 2006. $3+8$. 1977 .

8. References for the use of CUO(II) in industrial and environmental chemistr: (a) Guerreiro. E. D.: Gorriz. O. F.: Rivarola, J. B.; Arrua, L. A. Appl Catal At 1997, 165, 259. (b) Carniti. P: Gervasini, A.: Modica, V. H.: Ravsio. N. Appl. Catal B 2000. 28. 175. (c) Koryabkina. N. A.: Phatak. A. A.: Ruettinger. W. F.: Farrauto. R. J.: Ribeiro. F. H. J. Catal. 2003. 217. 233. (d) Martinez-Arias. A.: Hungria. A. B.: Fernandez-Garcia. M: Conesa. J. C.: Munuera. G. J. Phus. Chem. B 2004, 108. 17983 . (e) Bennici, S.: Auroux, A.; Guimon. C.: Gervasini, A. Chem Maten 2006. 18. 3641. (f) Gervasini. A.; Carniti. P.; Bennici. S.; Messi. C. Chem. Mater 2007. 19. 1319.

9. Recent references for CuO(II) nanoparticle-catalyzed reactions: (a) Rout. L.: Sent. T. K.: Punniyamuthy. T. Angew Chem. Int. Ed. 2007. t6, 1. (b) Kantam, M. L.; Laha, S.: Yadav. J:- Likhar, P. R: Sreedhar. B.: Choudary, B. M. Adv Symh. Catal. 2007.349, 1797 (c) Rout. L: Jammi. S.: Punnivamurthy. T. Org. Lett. 2007,9. 3397.

10. Zhu. T.: Li. D.: Chen. H.: Yang. X.: Lu. L.: Wang. X. Materials Lett. 2004. 58. 3324.

11. JCPDS-International Centre for Diffraction Data PCPDFFIN. V. 2.4: 2003.

12. Labbe. G. Chem. Rex $1969,69,345$

13. (a) Kulkarni. A. A.: Maki. K. Ong. Swnth. 2006. 83. 200. (b) Müller. P.: Imogaï. H. Tetrahedont Astmmen 1998. 9. 4419. (c) Hooper. N.: Beeching. L. J.: Dyke. J. M.: Morris. A.: Ogdent. T. S.: Dias. A. A.: Costa. M. L.: Barros, M. T: Cabral. M. H.; Moutinho. A. M. C.J. Plns. Chem A 2002. 106.9968.

14. (a) Appukkuttan, P.: Dehaen. W: Fokin, V. V: Van der Eycken. E. Org. Lett. 2004. 6. 4223. (b) Beckmantn. H. S. G. Wittmann. V. Org. Lett. 2007. 9. 1. 